\title{
Assessing the ability of rural agrarian areas to provide Cultural Ecosystem Services (CES): a Multi Scale Social Indicator Framework (MSIF)
}

Article

Accepted Version

Carvalho-Ribeiro, S. M., Pinto Correia, T., Paracchini, M. L., Schuepbach, B., Ode Sang, A., Vanderheyden, V., Southern, A., Jones, P., Contreras, B. and O'Riordan, T. (2016) Assessing the ability of rural agrarian areas to provide Cultural Ecosystem Services (CES): a Multi Scale Social Indicator Framework (MSIF). Land Use Policy, 53. pp. 8-19. ISSN 02648377 doi: https://doi.org/10.1016/j.landusepol.2015.04.024 Available at https://centaur.reading.ac.uk/40144/

It is advisable to refer to the publisher's version if you intend to cite from the work. See Guidance on citing.

To link to this article DOI: http://dx.doi.org/10.1016/j.landusepol.2015.04.024

Publisher: Elsevier

All outputs in CentAUR are protected by Intellectual Property Rights law, including copyright law. Copyright and IPR is retained by the creators or other copyright holders. Terms and conditions for use of this material are defined in the End User Agreement. 


\section{www.reading.ac.uk/centaur}

\section{CentAUR}

Central Archive at the University of Reading

Reading's research outputs online 
- Title

Assessing the ability of rural agrarian areas to provide Cultural Ecosystem Services (CES): A Multi Scale Social Indicator Framework (MSIF)

\section{- Author names and affiliations.}

Author 1: Carvalho-Ribeiro, Sónia

ICAAM- Instituto de Ciências Agrárias e Ambientais Mediterrânicas University of Évora. Núcleo da Mitra, Edifício Principal, Gab 202, Apartado 94, 7002-554 Évora,Portugal, Phone: + 351266740800 (ext 4445), email: sribeiro@uevora.pt

Author 2: $\quad$ Pinto Correia, Teresa. ICAAM- Instituto de Ciências Agrárias e Ambientais Mediterrânicas. DPAO - Department Landscape Environment and Planning,University of Évora (UE), Núcleo da Mitra, Edifício Principal, Gab 203, Apartado 94, 7002-554 Évora,Portugal, Phone: + 351266740800 (ext 4445), email, mtpc@uvora.pt

Author 3: $\quad$ Paracchini, Maria Luisa,

Joint Research Centre JRC, TP 262, 21020 Ispra, Italy phone +392332 789897 fax +39 0332785230 email luisa.paracchini@jrc.it

Author 4: $\quad$ Schuepbach, Beatrice.

Agroscope, Institute for Sustainability Sciences (ISS).Reckenholzstrasse 191.CH-8046

Zürich.Switzerland. phone: +4144377 7328 fax: +41 4437772 01. e-mail: beatrice.schuepbach@agroscope.admin.ch.

Author 5: $\quad$ Ode Sang, Asa

Swedish University of Agricultural Sciences. Phone:040-415428 email asa.sang@slu.se

Author 6: Vanderheyden, Vincent Université de Liège - Institut de géographie

Allée du Six-Août, 2 - Bât. B11 4000 Liège Belgium Phone : +32 43665265 email: vincent.vanderheyden@ulg.ac.be

Author 7: $\quad$ Southern, Adrian

The Royal Society for the Protection of Birds, 46 the Green, South Bar. Banbury. England. OX16 9AB Phone: +44 1295676464 email: adrian.southern@rspb.org.uk

Author 8: $\quad$ Jones, Philip

University of Reading, Centre for Agricultural Strategy, Reading UK. RG6 6AR. Email: p.j.jones@reading.ac.uk

Author 9: Beatriz Contreras

Author 10: $\quad$ Tim O’Riordan, Emeritus Professor,

University of East Anglia, School of Environmental Sciences, Phone + 441603810 534, email, t.oriordan@uea.ac.uk 
Current address:

Universidade Federal de Minas Gerais, Centro de Sensoriamento Remoto, Av. Antônio

Carlos, 6627, Belo Horizonte - MG, CEP 31270-900, Tel: +55 31 3409-5449 Fax: +55 31

40 3409-5410 sonia@csr.ufmg.br

\section{Abstract}

Assessing the ways in which rural agrarian areas provide Cultural Ecosystem Services (CES) is proving difficult to achieve. This research has developed an innovative methodological approach named as Multi Scale Indicator Framework (MSIF) for capturing the CES embedded into the rural agrarian areas. This framework reconciles a literature review with a trans-disciplinary participatory workshop. Both of these sources reveal that societal preferences diverge upon judgemental criteria which in turn relate to different visual concepts that can be drawn from analysing attributes, elements, features and characteristics of rural areas. We contend that it is now possible to list a group of possible multi scale indicators for stewardship, diversity and aesthetics. These results might also be of use for improving any existing European indicators frameworks by also including CES. This research carries major implications for policy at different levels of governance, as it makes possible to target and monitor policy instruments to the physical rural settings so that cultural dimensions are adequately considered. There is still work to be developed on regional specific values and thresholds for each criteria and its indicator set. In practical terms, by developing the conceptual design within a common framework as described in this paper, a considerable step forward towards the inclusion of the cultural dimension in European wide assessments can be made.

60

\section{$61 \quad$ Highlights}

62 - This work develops a Multi Scale Indicator Framework (MSIF)

63 - MSIF is able to include Cultural Ecosystem Services (CES) such as aesthetics into multi 64 scale assessments

65 - By using MSIF, rural areas' physical features were related to aesthetics, diversity and 66 stewardship criteria

67 - Agricultural areas with higher land uses/ land cover ratio likely fulfil societal demands 68 such as diversity, stewardship and aesthetics. 


\section{INTRODUCTION}

It is well established that agricultural and forestry activities in Europe, in addition to providing provisioning services, i.e. food, fuel and fibre, provide a variety of nonmaterial benefits to society. These include cultural ecosystem services (CES) such as: cultural identity; spiritual services (sacred, religious, or other forms of spiritual inspiration derived from ecosystems); inspiration (use of natural motifs or artefacts in art, folklore, etc.); aesthetic appreciation; and recreation and tourism (Burkhard, Kroll et al. 2009, Cooper, Hart et al. 2009, Sayadi, Gonzalez-Roa et al. 2009, García-Llorente, Martín-López et al. 2012, Pinto-Correia and Kristensen 2013). Societal demand for these cultural ecosystem services is well documented worldwide (MEA 2005, OECD 2006, TEEB 2010). In the European Union, for example, both the Common Agricultural Policy (CAP Pillar II, Axis 3) and the EU Biodiversity Strategy to 2020 (EU, 2011) recognise societal demand for CES by calling for the "maintenance, restoration and upgrading of the cultural and natural heritage of villages, rural landscapes and high nature value sites". However, despite such policy acknowlement, CES are not explicitly identifiable as policy instruments, but rather tend to be embedded within the landscape concept, with no attempt, for example, to link the maintenance of specific CES to landscape payments. Compounding this policy limitation is a lack of reliable assessment of the contributions of different farming systems, or farming practices, to the "nonmaterial" qualities embedded into different cultural ecosystem services, such as aesthetics, identity or diversity, meaning that these relationships are understood largely in terms of whole landscapes contributing to bundles of CES.

Given that agricultural/rural policy decisions implemented at one scale of governance may have consequences on the delivery of CES at other scales, there have been calls for the application of multi-scale approaches to policy setting and monitoring (Cash, Adger et al. 2006, Dick, Maes et al. 2014, Lefebvre, Espinosa et al. 2014). The relevant literature on this subject is scarce and this exposes a number of conceptual and methodological difficulties. Foremost among these difficulties is the mismatch between the spatial scale at which environmental processes operate and are measured and the spatial scale at which agricultural management operates, a fact that is often not systematically captured in theoretical frameworks used to link these processes (Pelosi, Goulard et al. 2010). Particular challenges arise from data aggregation methods and the 
101 establishment of indicators, as well as appropriate assessment of linkages across scales

102 (Volk and Ewert 2011).

103 Something which particularly needs to be addressed is the question of how to assess and measure different CES at multiple scales of governance. A well-established approach for understanding the ways in which rural agrarian areas provide goods and services to society is that of deriving criteria and indicators for assessing the ability of rural areas to provide such goods. The existing literature on such indicators is vast and the indicators proposed can be broadly categorized into: i) environmental indicators, for example the United Nations Statistics Division Environmental Indicators (UNSD, 2014); ii) sustainability indicators (including the social, economic and environmental dimensions); and iii) landscape indicators (including landscape visual characteristics). The scalability and generalizability of these different classes of indicators varies. While environmental indicators are transferable between sites and regions, landscape indicators cannot be applied everywhere (Cassatela and Peano 2011). For this reason studies contributing to the very rich body of empirical work assessing visual concepts and attributes for deriving preferences for rural agrarian areas are often framed within the context of specific landscapes (see Section 2.2.1). This fact raises concerns about the generalizability (Cassatela and Peano 2011) of landscape-based indicators between different scales of analysis, and implies that multi-scale assessment of this class of indicators would be very challenging (van Zanten, Verburg et al. 2014).

In spite of these limitations, however, this very rich theoretical and empirical work on landscape preferences and perceptions should not be thought of just as a collection of case studies (van Zanten, Verburg et al. 2014). We argue instead that exploring the diversity of landscape preferences expressed in this literature, through different

125 frameworks, might aid the development of a suitable framework for assessing the roles 126 and values of landscape and its elements in provision of cultural ecosystem services 127 (CES).

128 There is an extensive body of research on the assessment of the efficacy of public 129 policies and planning approaches for delivering public goods and ecosystem services. 130 However, the majority of the assessment frameworks proposed in this literature focus on fairly familiar environmental constructs, such as land use and water quality (for example, see the EU Common Monitoring Evaluation Framework (EC, 2006)) and do 
not comprehensively address cultural ecosystem services (Paracchini, Capitani et al. 2012). With the possible exception of recreation (Paracchini, Zulian et al. 2014), current indicators fail to provide effective frameworks for either measuring the progress of wider social welfare, or for developing or reforming policy to cope with newly emerging social problems (Ahn, Choi et al. 2012). So far, most attempts to include these wider values and services have encountered difficulties when seeking translation into policy. In consequence, none of the frameworks so far suggested have demonstrated their utility for assessing the effectiveness of current policies in delivering various public goods and ecosystem services (Arler 2000, Turpin, Dupraz et al. 2009, Paracchini, Pacini et al. 2011, Pinto-Correia, Machado et al. 2013).

This research aims to fill this gap by developing a methodological framework to evaluate the ways in which rural agrarian areas provide cultural ecosystem services (CES). We call this approach the Multi Scale Social Indicator Framework (MSIF). In order to address the multi scale issue, the framework distinguishes indicators into two groups based on whether they are (i) generalizable over all regions (G), or (ii) applicable only to one, or a few, specific regions (RS). In this context, an indicator is considered $\mathrm{G}$ if it is possible to apply it throughout Europe, even though its range and thresholds might vary from region to region. To provide examples, an indicator related to olive groves could only be applied in Mediterranean regions, and would therefore be classified as RS, while an indicator related to outdoor recreation is applicable to the whole of Europe and therefore would be classified as G.

This approach is built upon the assumption, supported by some previous studies, that it is possible to capture and assess societal preferences, in the context of the rural agrarian areas, at different spatial scales, ranging from the European, national and regional scales to the landscape and local level (Carvalho- Ribeiro, Madeira et al. 2013, Dick, Maes et al. 2014). Previous studies, when measuring societal preferences at broader spatial scales, have used a 'top-down' approach, based on use of proxy indicators (mostly environmental indicators), derived from Europe-wide datasets, often integrated into composite indices (for example, see Paracchini et al, Pinto Correia et al. and Jones et al this issue). At the local and regional scales, landscape preference surveys (see Section 2.1.2.), have used a 'bottom-up approach, eliciting data through primarily data collection, i.e. surveys, of the preferences of groups that are local to the specific landscape in question (for an example of this approach, see Almeida et al this issue). 
166 However, the problem of bridging these different scales remains unresolved, as is the

167 problem of how to validate the results from broader scale assessments, i.e. based on 168 proxy indicators, while overcoming downscaling issues (Mander, Muller et al. 2005).

169 The MSIF attempts to overcome these problems.

170 The effectiveness of any social indicator framework in capturing preferences for landscape hinges on the extent to which it can discern preferences from among the complex perceptions of rural agrarian settings in which they are embedded. In this context preferences towards rural landscapes are understood to be pre-cognitive responses to specific landscape features, elements or characteristics, which generate feelings of liking or disliking (Antrop 2000, Surova and Pinto-Correia 2008, Swanwick 2009, Carvalho-Ribeiro, Migliozzi et al. 2013). Perceptions, on the other hand, are cognitively based and hence more difficult to assess. As defined by Antrop (2000:19) "perception, as complex learning processes, analyses the observation immediately and interactively and links the results with our knowledge and past experience". In view of the subtly of these distinctions, and the difficulties involved in measuring perceptions, this study focuses predominantly on the preferences of society as a whole, and not on the particular preferences, or perceptions of individuals or particular user groups.

One further question that had to be addressed in constructing the MSIF is the possibility of achieving any kind of consensus on the list of measures to be used as indicators of the contribution of different elements of the physical rural agrarian areas to cultural ecosystem services. This study directly explores this issue and describes a novel approach for identifying and evaluating a range of possible measures/indicators that are both available and meaningful at multiple levels of governance. This study therefore addresses three broad questions:

1. Is it possible to identify a meaningful set of measures/indicators for conveying social preferences for the rural agrarian areas of Europe?

2. Are available measures/indicators only region specific, or can a set be defined that are broadly applicable to all rural agrarian areas of Europe?

194 3. At what scale(s) are these measures/indicators most meaningful, and as a corollary,

195 are these measures/indicators scalable and therefore relevant to inform policy making at 196 different levels of governance? 


\section{METHODOLOGICAL FRAMEWORK}

199 The research questions were addressed by means of a two-stage methodology:

200 1. A comprehensive literature review, based on a Science Direct web search.

201 2. A symposium and participatory workshop with scholars and practitioners in

202 landscape science was held, during the International Association of Landscape Ecology

203 (IALE EU) congress held in Manchester in September 2013 (http://www.iale2013.eu/).

204 The literature review explored the criteria and visual concepts /attributes relating to

205 preferences towards landscape by society as a whole. The participatory workshop was

206 designed as a forum for gathering assessments by landscape researchers and

207 practitioners on the characteristics, elements, or features of rural areas which contribute

208 to the criteria and visual concepts highlighted in the literature as important in preference

209 formation. As illustrated in Figure 1, the primary purpose of this study was to combine

210 these two methodologies to construct a robust framework of indicators (i.e. the MSIF)

211 capturing societal preference for rural agrarian areas, applicable to different spatial

212 scales, as a means to informing policy making at multiple levels of governance.

213

214 Figure 1 here

216 2.1 A SYSTHEMATIC LITERATURE REVIEW ON PREFERENCES BY 217 SOCIETY CONCERNING RURAL AGRARIAN AREAS OF EUROPE

218 The literature review was initiated using the advanced search tools available on the

219 Science Direct web platform (http://www.sciencedirect.com/science/search) using the

220 following search terms: "landscape preferences in Europe", "rural agrarian areas",

221 "scale" and "indicators". This search identified 466 articles in this topic area (as of June

222 2013). The literature review involved the identification, from within this body of

223 literature of multi-scale measures that might be suitable for use as indicators conveying

224 social preferences concerning rural agrarian areas (Flick 2002). This was followed by a

225 systematised classification of these measures as a means to making more sense out of

226 the disparate (and confusing) state of both theoretical and empirical work on societal

227 preferences for rural agrarian areas. The classification identified existing measures into

228 one of three hierarchical categories: i) criteria upon which preferences might be based

229 (preferences framed on a user based activity e.g. collecting mushrooms might be

230 different for the same individual's preferences for aesthetically pleasing landscapes); ii) 
visual concepts or attributes conveying preferences; and iii) features, elements or characteristics of the rural areas able to represent these concepts/attributes. This last group, at the base of the hierarchy, then formed the pool from which we hoped to derive a list of measures and ultimately a robust set of indicators (Tveit, Ode et al. 2006). The literature review found an extensive array of possible criteria and visual concepts which could be related to preferences for rural agrarian areas (presented in sections 2.1.1.and 2.1.2. respectively). In order to screen out unsuitable indicators, an approach proposed by Tveit et al (2006) was employed. This filters the selection according to a number of technical criteria, i.e. the soundness and clarity of the theoretical basis; transferability; quantifiability; mappability; availability; and policy relevance.

\subsubsection{A review of the criteria used to describe preferences for rural agrarian areas}

243 One of the major findings of the literature review is that preferences for rural agrarian areas vary markedly according to the criteria on which preference is expressed (Coeterier 1996, Gobster, Nassauer et al. 2007, Rogge, Nevens et al. 2007, Sevenant and Antrop 2009, Swanwick 2009, Sevenant and Antrop 2010). These criteria, which are anthropegenically mediated, may represent the nature of the interaction of the user with the landscape, or represent perceptions of physical or cultural aspects of the landscape (Coeterier 1996, Gobster, Nassauer et al. 2007, Rogge, Nevens et al. 2007, Sevenant and Antrop 2009, Swanwick 2009, Sevenant and Antrop 2010). Six criteria can be identified from the literature.

1. Preferences with a functional basis, largely in the context of a user based activity- for example, preferences of tourists (recreation, bird watching), preferences of hunters, etc. Here, preferences vary over specific user groups (Schmitz, De Aranzabal et al. 2007, Fyhri, Jacobsen et al. 2009);

2. Preferences on the basis of visual concepts such as: stewardship, coherence, disturbance, historicity, visual scale, imageability, diversity, naturalness and ephemera (Ode, Tveit et al. 2008, Fry, Tveit et al. 2009, Ode, Fry et al. 2009, Ode, Hagerhall et al. 2010, Ode and Miller 2011, Ode Sang and Tveit 2013);

3. Preferences for certain attributes of landscapes, such as refuge and security, or legibility and mystery (Appleton 1975, Appleton 1998, Kaplan and Kaplan 2011); 
4. Preferences based on scenery, i.e. scenic beauty, tranquility, etc. focussing on beautiful and idyllic countryside (Carlson 1977, Van Den Berg, Vlek et al. 1998, Daniel 2001, Barrett, Farina et al. 2009, Tempesta 2010)

5. Preferences in the context of landscape identity, i.e. elements of the physical landscape that conveys sense of place (Proshansky, Fabian et al. 1983, Duncan and Ley 1993) such as preferences for traditional farming practices-in some cases relating to quality and certified products (Antrop 1997, Sayadi, Gonzalez-Roa et al. 2009, Wu 2010, Stanchi, Freppaz et al. 2012); and

6. Preferences for particular types of land cover (Ulrich 1986, Dramstad, Fry et al. 2001, Dramstad, Tveit et al. 2006, Carvalho-Ribeiro, Ramos et al. 2013). Preferences for different land cover seem to vary across Europe. For example in southern Europe the montado agro forestry system is highly valued, whereas other land cover types e.g. orchards, are valued in other parts of Europe.

The authors' contend that using different "criteria" such as these for identifying and classifying preferences for rural agrarian landscapes is not only possible but also desirable. This assumption is based on an acknowledgement that the basis of preferences may vary, even for the same individual, according to the criteria by which their preferences are expressed. For example, preferences for someone picking berries, i.e. so called functional preferences, might be different from the same individual when seeking aesthetically pleasing landscapes, i.e. aesthetics (Tahvanainen, Tyrvainen et al. 2001).

The literature review also made clear that there is a need to further address visual concepts relating to landscape preferences, as this is a focus of a considerable body of work within the literature. This question is revisited in Section 2.1.2 below.

\subsubsection{A review of landscape preferences}

Before beginning the process of selecting an indicator set for the multi-scale indicator framework (MSIF) further consideration needs to be given to the landscape scale. The European Landscape Convention defines landscape as "an area, as perceived by people, whose character is the result of the action and interaction of natural and/or human 
factors" (ELC 2000). This definition captures the notion that landscape is a multi-

297 dimensional concept. Landscapes result from the ways that different components of the environment, both ecological (geology, soils, climate, flora and fauna) and cultural

299 (institutions formal and informal), and society as a whole, interact together in material and imaginary ways (Selman 2006). Modern theories therefore present landscapes as holistic entities, within which natural and human processes merge. Communities,

302 legislators, industry, local stakeholders and the public at large have different expectations from landscape, and their particular preferences all have an influence on landscape planning (McMichael, Butler et al. 2003). Whilst recognising that assessments must take place at multiple scales, the landscape scale itself is of particular importance, as it is here that conflicting interests, e.g. production and conservation, need to be coordinated (Tress, Tress et al. 2001). It is therefore here, at the landscape scale, that societal demands for cultural ecosystem services unfold and provision of them occurs (Selman 2006).

310 Because of the multi-dimensional nature of landscapes, the body of work on "landscape visual concepts" or "landscape attributes" is vast. A Web of Science search using these expressions as search terms undertaken in 2013 found 16,916 articles, and by April 2014 this number had risen to 18,046. Space does not permit a full review of such a

314 huge quantity of literature, or even a review solely of existing frameworks for analysing visual qualities, such as, for example, the Landscape Character Assessment (LCA)

316 (Swanwick 2002).

317 However, from the literature review a number of key concepts emerged as important in 318 determining preference for rural agrarian areas, such as the concept of stewardship.

319 While stewardship has been identified as an important determinant of landscape preference (Nassauer 2011, Ode Sang and Tveit 2013), the manner and extent of operation of stewardship remains obscure, in part because the effect seems to vary both between and within individuals and groups (Tips and Vasdisara 1986) and according to landscape context (Ode Sang and Tveit 2013). In this study, therefore, rather than try to identify a set of features, elements and characteristics contributing to preference for landscapes in general, we have constrained the analysis to landscapes under stewardship, i.e. where management gives the landscape a 'cared for' appearance. No attempt was made to identify variation in the weightings given to these elements, features or landscape characteristics reflecting relative importance expressed by 
different groups. However, the study did assess which of these features, elements and characteristics were and were not readily scalable.

331 Two further concepts identified in the literature review as important determinants of

332 societal preferences for landscape were diversity, i.e. the diversity embedded in

333 landscapes and the aesthetic values associated with landscapes (Ribe 1989, Hamilton

334 2001, Van Eetvelde and Antrop 2004, Ode, Hagerhall et al. 2010, Kaplan and Kaplan

335 2011, Ode and Miller 2011). The concern with these concepts, in the context of the

336 MSIF, is that considerable challenges have been demonstrated in trying to make them

337 operational as well as scalable. A number of rigorous studies have shown that both the

338 perceptions of diversity in landscapes and their associated aesthetic qualities are fully

339 anthropogenic and occur at a "human" scale dubbed the "perceptible realm" by Gobster

340 et al. (2007). Only a few researchers have taken up the challenge of

341 upscaling/downscaling indicators of diversity or aesthetics in order to frame cross scale

342 policy making.

343 In order to fully develop the MSIF, it will be necessary to build upon the work of

344 previous studies and identify, for each one of these criteria or visual concepts (see

345 Section 2.1.2) identified in the literature, i.e. stewardship, diversity or aesthetics, a list

346 of landscape features, elements or characteristics contributing to these. If this is

347 possible, it will be then be feasible to assess preferences by society as a whole at

348 different levels of governance. It was to explore these possibilities that the symposium

349 and participatory workshop mentioned in Section 2.2 were organized.

\subsection{SYMPOSIUM AND PARTICIPATORY WORKSHOP}

351

352

353

Seven papers presented during a symposium of the IALE 2014 conference (http://www.iale2013.eu/scaling-social-indicators) were identified which focussed on the three research questions introduced at the end of the Introduction section above. The authors of these papers, along with other expert stakeholders, subsequently attended the workshop where the criteria/visual concepts of stewardship, diversity and aesthetics as described in Section 2.1.1 were tested. Three "stations" or discussion areas were located in the room, each with a wall-mounted table to collect stakeholder input on one of the criteria/visual concepts. Alongside each table (see Table 1) was a full definition of each of the criteria/visual concepts, accompanied by the following generic discussion question: 
364 In each one of these "stations" one facilitator helped participants to fill in the wallmounted table (Figure 2).

Figure 2 here

367 The participants moved around the stations in a carrousel approach. As soon as the 368 participants arrived at each station, the facilitators read the definition of the criteria and prompted the discussion by reading the question.

370 Participants were given 15 minutes at each station. If a participant suggested a possible

371 indicator, the facilitator prompted discussion of that suggestion among the other

372 members of the group. There was no imperative to reach agreement within the group on 373 the choice of features or characteristics for use as indicators for the different criteria; the 374 only requirement was to discuss each suggestion within the group. The tables were

375 filled in one row at a time, to collect specific data and judgements about each suggested 376 indicator using the columns in the table. The same measure/ indicator could be repeated 377 for different criteria/visual concepts. The group discussions were tape recorded. Each 378 time the group changed station, the facilitators changed the colour of their pen so that 379 the contributions of each participant group could be subsequently identified. This 380 permitted the post-workshop identification of participants with particular sets of 381 indicators. After this carrousel exercise there was a plenary discussion. To start the 382 plenary session participants were asked to vote, i.e. expressing their own preferences, on 383 the relevance of each suggested indicator. They did this by sticking five coloured dots 384 against indicators at the three stations. Participants could place one dot against each of 385 the five most relevant indicators, or place multiple dots against any single indicator to 386 express weighting. Following the voting, indicators and their scores were presented to 387 the whole group by the facilitator of each station. This was followed by a group 388 discussion and an evaluation of the session.

\section{RESULTS}


This results section is organized into two sub-sections: Section 3.1 covers the content of the indicator dataset derived from the workshop; while Section 3.2 describes and critiques the process by which the data in the indicator dataset was gathered, and then considers ways in which the three research questions can be answered using this data.

\subsection{The proposed indicator set}

Table 2 shows, for the three criteria analysed, i.e. stewardship, diversity, aesthetics

396 (column 1), the set of potential measures/indicators that were derived from the

397 workshop participants (column 2). Column 3 of the table shows the score that each

398 measure/indicator obtained in the voting. Column 4 highlights the possibility of

399 measuring each indicator at different geographical scales and Column 5 classifies

400 measures/ indicators as either Region Specific (RG) or General $(G)$ on the basis of their

401 level of generalizability.

402

403 A set of 40 putative indicators were gathered from the three workshop stations (see 404 anexxe1). From the 13 indicators identified with stewardship, those that scored highest 405 in the voting were:

- “quality" of man-made structures, and

- man-made structures with a function

408

409

410

Both of these indicators denote active farm management. Twelve diversity indicators were suggested, with three scoring highly in the voting:

- edges between agriculture and other land uses

- the number of elements and land covers in a view shed, and

- high diversity indexes (e.g. Simpson's Diversity Index 'D' or Shannon Index 'H')

For aesthetics, high voting scores were obtained for two of the 15 suggestions, namely:

- water bodies

- sublime features (such as mountains)

Some of the workshop participants noted (see Section 3.2.2) that some of the measures/indicators listed in annexe 1 cannot be classified, because of various limitations. To remove these weaker measures the list of measures was filtered using an 
approach proposed by Tveit et al (2006) (please see the filtering criteria in Section 2.1. and the detailed assessment in Annexe 1). The results of this filtering exercise are shown in Table 2.

423 A review of all the measures/indicators retained after the filtering exercise ( Table2)

424 revealed that some physical landscape characteristics, or features, are important

425 contributors for more than one of the three preference criteria.The indicators that are 426 important to more than one criteria are shaded in grey. For example, hedges were 427 identified to as important for both the stewardship and diversity criteria. Also, 428 traditional elements/features were felt to be important for both stewardship and 429 aesthetics, while the presence of waste/litter is negative for both stewardship and 430 aesthetics. There are two landscape elements and characteristics that are important for 431 all 3 criteria. Those are (i) elements indicating traditional farming practices and 432 activities and (ii) a high number of land uses on a land cover type (i.e. a high land 433 use/land cover ratio)(Table 2 Columns 6 and 7, respectively ).

\subsubsection{The process of gathering the list of indicators}

The workshop involved 16 participants from 7 different countries: Greece, Belgium, Italy, the Netherlands, Switzerland, Germany, Japan, Poland, Norway, the UK and Portugal. There were four participants with landscape planning and management expertise, three with expertise in geography, two in environmental sciences (agriculture and forestry), one in biology (biodiversity), two in economic sciences, and one in psychology. Thirteen out of 16 participants were academic researchers (including principal investigators, post-doctoral researchers and $\mathrm{PhD}$ students) and three participants considered themselves to be practitioners. The majority of the participants (14 out of 16) classified the workshop as well organized, while 12 out of 16 felt they were able to communicate and were listened to. The aspects of the workshop that participants liked the most were the organization of the event and the opportunity for brainstorming (14 out of 16).

447 The three aspects of the workshop that the participants liked the least were the lack of 448 time for discussion (identified as a problem by five participants), the fact that the 449 facilitators handled discussions around the three criteria in different ways (identified by 450 four participants), and that some of the concepts being suggested were ambiguous and might have been explained to the group at an earlier stage (identified by four 
participants). Participants also experienced some difficulties in accepting other people's

453 views on these topics. In addition, the dominance of particular individuals also apparently hampered the participatory process to some extent. Six of the participants (around a third) were not completely satisfied with the outcomes of the workshop, pointing out that more work was needed on refining the list of indicators suggested by 457 participants.

458 As already indicated, it was to address this particular concern that the indicators were 459 subsequently filtered to derive a final robust set of 29 (out of 40) indicators using the 460 approach suggested by Tveit et al (2006) (Annexe1, where retained indicators are shaded grey). It should be noted that some of these 29 indicators scored relatively poorly on data availability and in order to retain them it was necessary to make some assumptions about the feasibility of additional data collection at moderate costs. There are still several screening issues that still need addressing and this work on indicator selection is progressing. Despite these remaining data quality issues, the data gathered at the workshop suggests that it is indeed possible to achieve some degree of consensus on a list of meaningful and relevant indicators for the three criteria/visual concepts. As participants came from a range of disciplines and geographical regions, there was considerable heterogeneity in the suggested measures and justifications for these. This suggests that it would have been very difficult to achieve complete agreement on all indicators, a view supported by the fact that some participants voiced strong opposition to some suggestions.

Addressing the first of three research questions, it can be stated that, although arguments remain on the relevance and validity of some of the indicators proposed, this study has at least demonstrated that this methodological approach is sufficiently robust to derive a preliminary indicator set appropriate for the MSIF. In addressing the second of the research questions, it was expected, a priori, that the majority of indicators would be framed in a region-specific manner due to issues of 479 landscape specificity. However, the results of the workshop demonstrated (see Column 4805 , Table 2) that the majority of the indicators can be classified as general (G) - meaning that it would be possible to use them throughout Europe, even though their range and thresholds might vary from region to region (please see * in Table 2). The workshop participants did identify a few RS indicators, such traditional irrigation systems, which are prominent only in Southern Europe due to drier climate. It is perhaps important to 
485

486

487

488

489

490

491

492

493

494

495

496

497

498

499

500

501

502

503

504

505

506

507

508

509

510

511

512

513

514

515

516

517

reflect on these results in light of the background of the workshop participants. Participants were generally experienced academic researchers and practitioners they were therefore very knowledgeable on what indicators might be applied everywhere, or only locally. A less experienced group might have drawn more on the specificities of the rural areas they were personally familiar with, rather than thinking in more general terms.

In terms of the third and final research question, i.e. the scalability of indicators, as shown in column 4 , the majority of the potential indicators elicited by participants can be measured at a range of spatial scales (and therefore levels of governance): namely site, landscape, regional and national scales. Indeed most can be derived through the use of high resolution satellite imagery, using both remote sensing and GIS technologies. It should be pointed out, however, that many of the indicators believed to be available through remote sensing, would only be available for the whole of Europe with an enormous input of time and financial resources. This is a significant problem which the use of MSIF needs to address. One cost effective way of approaching the data acquisition issue would be to deploy expenditures preferentially on those indicators that contribute to more than one criteria/visual concept and which better target policy across different levels of governance. Our suggestion would be to focus on the land uses/land cover ratio, as this also will tell us about the level of multi-functionality- this being an important issue to other policy instruments within CAP, particularly Pillar II.

\section{DISCUSSION}

In addition to providing provisioning outputs, agricultural and forest areas are today understood and expected to meet multiple societal demands (Pinto Correia and Carvalho Ribeiro 2012, Pinto-Correia and Kristensen 2013). In spite of policy recognition of this fact, societal expectations for, and provision of, cultural ecosystem services from rural landscapes barely register in extant indicator datasets, official or otherwise (Paracchini, Zulian et al. 2014).

Cultural ecosystem services (e.g. aesthetics) delivered by sites, landscapes or other geographical units, are particularly difficult to assess due to their multi-faceted and often perception-based nature. One of the innovations of the current study is that it builds upon the theoretical and empirical work of landscape sciences, particularly in the areas of landscape preferences, landscape attributes and visual concepts, as a means to 
518 characterising cultural ecosystem services. We have demonstrated the usefulness of such an approach through the construction of the MSIF framework, through which bundles of cultural ecosystem services provided by rural areas can be framed into a set of three criteria, with associated indicators, to account for societal preferences. In addition, the study has identified, by means of a literature review and participatory workshop, through a transdisciplinary approach, the links between the material/physical

524 elements of landscapes and the different cultural ecosystem services that they provide.

525 Previous work on landscape preferences has not notably addressed the issues involved 526 in upscaling/downscaling of societal preferences for rural agrarian areas. The few studies that have touched on scale issues have been limited to reviews of landscape preference case studies through meta-analysis (van Zanten, Verburg et al. 2014). The authors' contend that, because MSIF achieves multiple goals simultaneously, i.e. it: (i) engages with the complexity of findings from a comprehensive set of landscape preference studies; (ii) frames landscape preferences into different "criteria"/“visual concepts" linked to different cultural ecosystem services; and (iii) identifies features linked to these criteria/visual concepts that can be mapped at different scales of governance, it successfully addresses the ways in which physical landscape elements contribute to the non-material qualities of different CES. Further, the MSIF addresses not only the issue of upscaling/downscaling of rural landscape preferences, but also goes some way to understanding how elements of the physical landscape contribute to the bundle of cultural ecosystem services generated by rural agrarian landscapes. This represents considerable innovation.

540 The results of the study have shown that it is indeed possible to build a "moderately consensual" list of indicators for conveying aesthetics, stewardship and diversity of rural agrarian areas in Europe. The process of gathering this list of indicators was very much "negotiated" amongst participants, in spite of strong divergences of opinion. For example, where participants defended their favoured indicators rigidly, negotiation could become very complex. Because the workshop was held during an interdisciplinary conference, participants came from a diversity of backgrounds, i.e.

547 social sciences, environmental sciences and geography, encompassing both researchers 548 and practitioners and this contributed to the heterogeneity of the workshops outputs. 549 Fortunately, there was a clear commitment within the participating group to deal with problems that may arise from this inter-disciplinarity and they welcomed the challenge 
551 involved in this task and made a serious effort to ensure the quality of the outcomes.

552 This goal was facilitated by a recognition that good dialogue between participants from 553 different backgrounds was imperative. Even with a very high commitments from all the 554 stakeholders involved into the exercise, from a total of 40 possible indicators elicited by 555 workshop participants, only 29 met the criteria of robustness as adapted from the work 556 of Tveit et al (2006). Those 29 were afterwards screened, to eliminate overlap and 557 ambiguity, yielding 19 unique and preliminary indicators. Review of these data revealed 558 that some landscape elements, such as hedges, are important for more than one criterion 559 (stewardship and diversity). It is therefore likely these particular indicators, where they 560 exist, will be among the most useful for the assessment of cultural ecosystem services, 561 particularly if these are further developed through qualitative analyses of complimentary 562 data (e.g. data for the conservation status of hedges).

563 It is recognised that measuring some of these indicators would be both time consuming 564 and very expensive. For example, vertical diversity, or land uses:land cover ratio are 565 difficult to measure when using information derived from remote sensing alone. Thus it 566 would be necessary to reconcile remote sensing data with field surveys. Although there are already some widely available field survey datasets available, (for example the

568 Eurostat LUCAS survey, http://ec.europa.eu/eurostat/statistical-

569 atlas/gis/viewer/?myConfig=LUCAS-2012.xml), which include photographs of each 570 data point, it is still not known whether this is adequate for creating indicators such as 571 vertical diversity, or land uses:land use ratio, in a systematic manner. Therefore a 572 continuous monitoring of these elements, namely through remote sensing and GIS 573 technologies, might further help to develop this indicator set. As these elements and 574 characteristics can be measured through time and at multiple scales, it is possible to 575 derive list of those that, if properly addressed and calculated, might help to frame policy 576 making at multiple levels of governance. For example in Europe there are, at the 577 moment, two operational indicators sets, namely the EU agri-environmental indicators 578 (AEI) and the Common Monitoring Evaluation Framework (CMEF). While AEI 579 monitor the integration of environmental concerns into the CAP, the common 580 monitoring and evaluation framework (CMEF) measures the performance of the CAP 581 both in Pillar I and II. By definition, the AEI framework focuses on the environment, 582 but includes some indicators belonging to the social domain, such as "farmers' training 583 levels and use of environmental farm advisory services" and "risk of land 584 abandonment", necessary to build a storyline of the reasons why integration of 
585

586

587

588

589

590

591

592

593

594

595

596

597

598

599

600

601

602

603

604

605

606

607

608

609

610

611

612

613

614

environmental concern in the CAP may or may not have happened. The CMEF framework hosts instead a more consistent number of social indicators, since some of the CAP objectives specifically aim at improving the social context of rural areas, such as "Improving the competitiveness of the agricultural and forestry sector" and "Improving the quality of life in rural areas". The indicators presented in this work (Table 1) can be of use for enhancing the CMEF framework. One indicator that might be of particular interest is the land uses/land cover ratio. High ratio scores suggests that the more uses that are made of a single land cover the more likely it is that a rural area will be able to fulfill criteria such as aesthetics, diversity and stewardship. The land uses/land cover ratio can be assessed on the basis of a combination of land cover maps with agricultural data (Verburg and Overmars 2009, Verburg, van de Steeg et al. 2009). There are land cover maps at different spatial scales (e.g. CORINE for the whole Europe and different member country land cover databases). However, it is acknowledged that CORINE land-cover classes might hide considerable diversity of land uses and ecosystem service provision in contrasting European areas. Another related issue is that for some of the social indicators even a high resolution land cover map might not provide the details needed. As an alternative, there are farm-databases, such as FADN ${ }^{1}$ and $\mathrm{FSS}^{2}$, which provide relatively easy-access data for land use. This work shows that having data on landscape elements such as hedges, water bodies, litter, traditional farming practices, as well as data on land uses/land cover ratio, can be informative for assessing the ability of rural agrarian areas in supplying cultural ecosystem services. This might contribute to better target policy making by relating those social dimensions to physical rural settings. This is a crucial test for the achievement of the EU Biodiversity Strategy to 2020 targets. A main target of the Strategy is to map and assess ecosystems and their services. In MAES (EC, 2014) it is reported that cultural ecosystem services for agro-ecosystems can be mostly calculated on the basis of data which may be regionally available, while for some of these services further conceptual development is needed. The approach presented in this study fills an important gap, related to the possibility of calculating indicators for cultural ecosystem services at the EU level. This is very important as integrated assessments in this

\footnotetext{
${ }^{1}$ FADN http://ec.europa.eu/agriculture/rica/database/database.cfm ${ }^{2}$ Farm Structure Survey http://epp.eurostat.ec.europa.eu/cache/ITY_SDDS/EN/ef_esms.htm both (accessed 27.05.2014)
} 
category are currently severely under-represented (EC, 2014). Furthermore, results presented in this study provide an important conceptual advance for the inclusion of cultural ecosystem services in established indicator frameworks on which EU policy assessments are based (e.g. Eurostat agri-environmental indicators, CMEF indicators etc).

What still is missing in the evaluation undertaken here is the required thresholds of the indicator set to each regional context. Some indicators (i.e. hedges) do not have the same role everywhere, while diversity in land cover compositions can be valued differently in different regions. The way to approach these regional specificities still needs to be developed through a European-wide framework. It is therefore necessary to put the regional contexts into the broader European picture. The merits of different approaches to fine-tune this approach, together with suggestions for improving the workshop process are discussed in Table 3.

628 Table 3 here.

\section{CONCLUSION}

630 Three major research questions set the frame of this study. The first question asked: "Is 631 it possible to summarize a reliable set of insightful measures/indicators for conveying 632 societal preferences for rural agrarian landscapes of Europe?” Both the literature 633 review and the transdisciplinary process developed through the workshop revealed that 634 it is indeed possible to derive a moderate consensus on a list of indicators and so the 635 work on elaborating such list needs to be continued.

636 Question 2: "Are these indicators region specific? Or is there a set that can be said to 637 be generally applicable for all the rural agrarian landscapes of Europe?" The majority 638 of the indicators can be classified as general $(\mathrm{G})$, meaning that it is possible to use them 639 throughout Europe, although value ranges and thresholds might vary from region to 640 region. Consolidation of thresholds and ranges regionally still needs to be developed.

641 Question 3: "At what geographical scale(s) are these measures/indicators be most 642 meaningful? Is it possible to transfer a selected set of measure/indicators across scales 643 in such a way those can inform policy making at different scales of governance?" The 644 majority of possible indicators elicited by participants can be derived at multiple scales 645 of governance, namely: site, landscape, regional and national scales, mostly through the 
646

647

648

649

650

651

652

653

654

655

656

657

658

659

660

661

662

663

664

665

666

667

668

669

670

671

672

673

674

675

676

677

678

use of high resolution satellite imagery, using both remote sensing and GIS technologies.

From a policy perspective these findings suggest that it would be possible to undertake Europe-wide assessments of societal preferences for a number of critical land use strategies across Europe. This could include the extension of the biodiversity and habitat enhancement strategies, the widening of the rural forestry and tourism programmes, the introduction of aesthetics and stewardship considerations to ecological assessments, and the scope for designing landscapes of health and exercise as part of any forthcoming wellbeing strategy. What is particularly exciting is that this work could lead to a better participatory planning process for designing fresh approaches to the shaping of ecological and cultural values for "new landscapes".

These results might also be of use for improving existing European indicators frameworks by incorporating cultural ecosystem service provision into them. This would likely have major implications for policy at different levels of governance, as this would make it possible to target to, and monitor policy instruments in, physical rural settings so that the cultural dimension is adequately considered. Taking into consideration the diversity of landscape and regional contexts in Europe, there is still work to be done to allow for region-specific values and thresholds to be applied to each criteria and its indicator set. In practical terms, by developing the conceptual design within a common framework, as described in this paper, using common data sets and sources, a considerable step towards to the inclusion of the cultural ecosystem services in official European wide assessments can be made.

\section{ACKNOWLEDGEMENTS}

We are grateful to all workshop participants for their essential contribution to the study. Special thanks go to the organising staff of the IALE Europe Conference http://www.iale2013.eu/. Acknowledgements are also due to the Portuguese Science Foundation (FCT) for the funding provided to the post-doctoral scholarship under which the lead author undertook this work (reference SFRH/BPD/69329/2010). This work was funded by FEDER Funds through the Operational Programme for Competitiveness Factors - COMPETE and National Funds through FCT - Foundation for Science and Technology under the Strategic Project PEst-C/AGR/UI0115/2011. 


\section{REFERENCES}

Ahn, S.-H., Y. Choi and Y.-M. Kim (2012). "Static Numbers to Dynamic Statistics: Designing a Policy-Friendly Social Policy Indicator Framework." Social Indicators Research 108(3): 387-400.

Antrop, M. (1997). "The concept of traditional landscapes as a base for landscape evaluation and planning. The example of flanders region." Landscape and Urban Planning 38(1-2): 105-117.

Antrop, M. (2000). "Background concepts for integrated landscape analysis." Agriculture Ecosystems \& Environment(77): 17-28.

Appleton, J. (1975). The Experience of Landscape. London \& New York, Wiley. Appleton, J. (1998). "Living in the landscape: Toward an aesthetics of environment." British Journal of Aesthetics 38(1): 104-105.

Arler, F. (2000). "Aspects of landscape or nature quality." Landscape Ecology 15(3): 291-302.

Barrett, T. L., A. Farina and G. W. Barrett (2009). "Aesthetic landscapes: An emergent component in sustaining societies." Landscape Ecology 24(8): 1029-1035.

Burkhard, B., F. Kroll, F. Müller and W. Windhorst (2009). "Landscapes' Capacities to Provide Ecosystem Services - a Concept for Land-Cover Based Assessments." Landscape Online 15: 1-22.

Carlson, A. A. (1977). "On the possibility of quantifying scenic beauty." Landscape Planning 4(C): 131-172.

Carvalho- Ribeiro, S. M., L. Madeira and T. Pinto Correia (2013). "Developing comprehensive indicators for monitoring rural policy impacts on landscape in Alentejo, Southern Portugal." Danish Journal of Geography 113(2): 87-96.

Carvalho-Ribeiro, S. M., A. Migliozzi, G. Incerti and T. Pinto Correia (2013). "Placing land cover pattern preferences on the map: bridging methodological approaches of landscape preference surveys and spatial pattern analysis." Landscape and Urban Planning 114: 53- 68.

Carvalho-Ribeiro, S. M., I. L. Ramos, L. Madeira, F. Barroso, H. Menezes and T. Pinto Correia (2013). " Is land cover an important asset for addressing the subjective landscape dimensions?" Land Use Policy 35: 50-60

Cash, D. W., W. N. Adger, F. Berkes, P. Garden, L. Lebel, P. Olsson, L. Pritchard and O. Young (2006). "Scale and cross-scale dynamics: Governance and Information in a multilevel World." Ecology \& Society 11(2): [online] URL http://ecologyandsociety.org/vol11/iss12/art18/.

Cassatela, C. and A. Peano (2011). Landscape Indicators: Assessing and Monitoring landscape quality.

Coeterier, J. F. (1996). "Dominant attributes in the perception and evaluation of the Dutch landscape." Landscape and Urban Planning 34(1): 27-44.

Cooper, T., K. Hart and D. Baldock (2009). Provision of Public Goods through Agriculture in the European Union Report Prepared for DG Agriculture and Rural Development, Contract No 30-CE-0233091/00-28, Institute for European Environmental Policy IEEP. London.

Daniel, T. C. (2001). "Whither scenic beauty? Visual landscape quality assessment in the 21 st century." Landscape and Urban Planning 54(1-4): 267-281.

Dick, J., J. Maes, R. I. Smith, M. L. Paracchini and G. Zulian (2014). "Cross-scale analysis of ecosystem services identified and assessed at local and European level." Ecological Indicators 38(0): 20-30. 
Dramstad, W. E., G. Fry, W. J. Fjellstad, B. Skar, W. Helliksen, M. L. Sollund, M. S. Tveit, A. K. Geelmuyden and E. Framstad (2001). "Integrating landscape-based values - Norwegian monitoring of agricultural landscapes." Landscape and Urban Planning 57(3-4): 257-268.

Dramstad, W. E., M. S. Tveit, W. J. Fjellstad and G. L. A. Fry (2006). "Relationships between visual landscape preferences and map-based indicators of landscape structure." Landscape and Urban Planning 78(4): 465-474.

Duncan, J. and D. Ley (1993). "Place/ culture/ representation." Place/ culture/ representation.

ELC (2000). The European Landscape Convention, Council of Europe. Strasbourg. Flick, U. (2002). An Introduction to qualitative research. London.

Fry, G., M. S. Tveit, A. Ode and M. D. Velarde (2009). "The ecology of visual landscapes: Exploring the conceptual common ground of visual and ecological landscape indicators." Ecological Indicators 9(5): 933-947.

Fyhri, A., J. K. S. Jacobsen and H. Tømmervik (2009). "Tourists' landscape perceptions and preferences in a Scandinavian coastal region." Landscape and Urban Planning 91(4): 202-211.

García-Llorente, M., B. Martín-López, I. Iniesta-Arandia, C. A. López-Santiago, P. A. Aguilera and C. Montes (2012). "The role of multi-functionality in social preferences toward semi-arid rural landscapes: An ecosystem service approach." Environmental Science \& Policy 19-20(0): 136-146.

Gobster, P. H., J. I. Nassauer, T. C. Daniel and G. Fry (2007). "The shared landscape: what does aesthetics have to do with ecology?" Landscape Ecology 22: 959-972.

Hamilton, A. (2001). "Aesthetics and the environment: The appreciation of nature, art and architecture." British Journal of Aesthetics 41(4): 444-446.

Kaplan, R. and S. Kaplan (2011). "Anthropogenic/anthropogenerous: Creating environments that help people create better environments." Landscape and Urban Planning 100(4): 350-352.

Lefebvre, M., M. Espinosa, S. Paloma Gomez, M. L. Paracchini, A. Piorrc and I. Zasadac (2014). "Agricultural landscapes as multi-scale public good and the role of the Common Agricultural Policy." Journal of Environmental Planning and Management.

Mander, U., F. Muller and T. Wrbka (2005). "Functional and structural landscape indicators: Upscaling and downscaling problems." Ecological Indicators 5(4): 267-272.

McMichael, A. J., C. D. Butler and C. Folke (2003). "New visions for adressing sustainability." Science 302(12 December): 1919-1920.

MEA (2005). Ecosystems and Human Well-being. Synthesis., World Health Organization.

Nassauer, J. I. (2011). "Care and stewardship: From home to planet." Landscape and Urban Planning 100(4): 321-323.

Ode, A., G. Fry, M. S. Tveit, P. Messager and D. Miller (2009). "Indicators of perceived naturalness as drivers of landscape preference." Journal of Environmental Management 90(1): 375-383.

Ode, A., C. M. Hagerhall and N. Sang (2010). "Analysing Visual Landscape Complexity: Theory and Application." Landscape Research 35(1): 111-131.

Ode, A. and D. Miller (2011). "Analysing the relationships between indicators of landscape complexity and preference." Environmental Planning B: Planning \& Design 38: 24-40. 
Ode, A., M. S. Tveit and G. Fry (2008). "Capturing landscape visual character using indicators: Touching base with landscape aesthetic theory." Landscape Research 33(1): 89-117.

Ode Sang, A. and M. S. Tveit (2013). "Perceptions of stewardship in Norwegian agricultural landscapes." Land Use Policy 31(0): 557-564.

OECD (2006). The new rural paradigm. Policies and governance. Paris, OECD

Paracchini, M. L., C. Capitani, A. M. Schmidt, E. Andersen, D. M. Wascher, P. J. Jones, R. Simoncini, S. Carvalho Ribeiro, G. H. Griffiths, S. R. Mortimer, L. Madeira, I. Loupa Ramos and T. Pinto Correia (2012). Measuring societal awareness of the rural agrarian landscape: indicators and scale issues. EUR 25192 EN - 2012, Joint Research Centre.

Paracchini, M. L., C. Pacini, M. L. M. Jones and M. Pérez-Soba (2011). "An aggregation framework to link indicators associated with multifunctional land use to the stakeholder evaluation of policy options." Ecological Indicators 11(1): 71-80.

Paracchini, M. L., G. Zulian, L. Kopperoinen, J. Maes, J. P. Schägner, M. Termansen, M. Zandersen, M. Perez-Soba, P. A. Scholefield and G. Bidoglio (2014). "Mapping cultural ecosystem services: A framework to assess the potential for outdoor recreation across the EU." Ecological Indicators 45(0): 371-385.

Pelosi, C., M. Goulard and G. Balent (2010). "The spatial scale mismatch between ecological processes and agricultural management: Do difficulties come from underlying theoretical frameworks?" Agriculture, Ecosystems \& Environment 139(4): 455-462.

Pinto-Correia, T. and L. Kristensen (2013). "Linking research to practice: The landscape as the basis for integrating social and ecological perspectives of the rural." Landscape and Urban Planning 120(0): 248-256.

Pinto-Correia, T., C. Machado, F. Barroso, P. Picchi, N. Turpin, J.-P. Bousset, N. Chabab and Y. Michelin (2013). "How do policy options modify landscape amenities? An assessment approach based on public expressed preferences." Environmental Science \& Policy 32(0): 37-47.

Pinto Correia, T. and S. M. Carvalho Ribeiro (2012). "The Index of Function Suitability (IFS): A new tool for assessing the capacity of landscapes to provide amenity functions." Land Use Policy 29(1): 23-34.

Proshansky, H. M., A. K. Fabian and R. Kaminoff (1983). "Place-identity: Physical world socialization of the self." Journal of Environmental Psychology 3(1): 5783.

Ribe, R. G. (1989). "The aesthetics of forestry: What has empirical preference research taught us?" Environmental Management 13(1): 55-74.

Rogge, E., F. Nevens and H. Gulinck (2007). "Perception of rural landscapes in Flanders: Looking beyond aesthetics." Landscape and Urban Planning 82(4): 159-174.

Sayadi, S., M. C. Gonzalez-Roa and J. Calatrava-Requena (2009). "Public preferences for landscape features: The case of agricultural landscape in mountainous Mediterranean areas." Land Use Policy 26: 334-344.

Schmitz, M. F., I. De Aranzabal and F. D. Pineda (2007). "Spatial analysis of visitor preferences in the outdoor recreational niche of Mediterranean cultural landscapes." Environmental Conservation 34(4): 300-312.

Selman, P. (2006). Planning at the landscape scale. London and New York, Routledge. 
Sevenant, M. and M. Antrop (2009). "Cognitive attributes and aesthetic preferences in assessment and differentiation of landscapes." Journal of Environmental Management 90(9): 2889-2899.

Sevenant, M. and M. Antrop (2010). "Transdisciplinary landscape planning: Does the public have aspirations? Experiences from a case study in Ghent (Flanders, Belgium)." Land Use Policy 27(2): 373-386.

Stanchi, S., M. Freppaz, A. Agnelli, T. Reinsch and E. Zanini (2012). "Properties, best management practices and conservation of terraced soils in Southern Europe (from Mediterranean areas to the Alps): A review." Quaternary International 265: $90-100$.

Surova, D. and T. Pinto-Correia (2008). "Landscape preferences in the cork oak Montado region of Alentejo, southern Portugal: Searching for valuable landscape characteristics for different user groups." Landscape Research 33(3): 311-330.

Swanwick, C. (2002). Landscape Character Assessment. Guidance for England and Scotland, Scottish Natural Heritage

Swanwick, C. (2009). "Society's attitudes to and preferences for land and landscape." Land Use Policy 26(Supplement 1): S62-S75.

Tahvanainen, L., L. Tyrvainen, M. Ihalainen, N. Vuorela and O. Kolehmainen (2001). "Forest management and public perceptions - visual versus verbal information." Landscape and Urban Planning 53(1-4): 53-70.

TEEB (2010). "Chapter 2 Biodiversity, ecosystems and ecosystem services ".

Tempesta, T. (2010). "The perception of agrarian historical landscapes: A study of the Veneto plain in Italy." Landscape and Urban Planning 97(4): 258-272.

Tips, W. E. J. and T. Vasdisara (1986). "The influence of the socio-economic background of subjects on their landscape preference evaluation." Landscape and Urban Planning 13(Short communication): 225-230.

Tress, B., G. Tress, H. Decamps and A. M. d'Hauteserre (2001). "Bridging human and natural sciences in landscape research." Landscape and Urban Planning 57(3-4): 137-141.

Turpin, N., P. Dupraz, C. Thenail, A. Joannon, J. Baudry, S. Herviou and P. Verburg (2009). "Shaping the landscape: Agricultural policies and local biodiversity schemes." Land Use Policy 26(2): 273-283.

Tveit, M., A. Ode and G. Fry (2006). "Key concepts in a framework for analysing visual landscape character." Landscape Research 31(3): 229-255.

Ulrich, R. S. (1986). "Human responses to vegetation and landscapes." Landscape and Urban Planning 13(C): 29-44.

Van Den Berg, A. E., C. A. J. Vlek and J. F. Coeterier (1998). "Group differences in the aesthetic evalution of nature development plans: A multilevel approach." Journal of Environmental Psychology 18(2): 141-157.

Van Eetvelde, V. and M. Antrop (2004). "Analyzing structural and functional changes of traditional landscapes - two examples from Southern France." Landscape and Urban Planning 67(1-4): 79-95.

van Zanten, B. T., P. H. Verburg, M. J. Koetse and P. J. H. van Beukering (2014). "Preferences for European agrarian landscapes: A meta-analysis of case studies." Landscape and Urban Planning 132(0): 89-101.

Verburg, P. H. and K. P. Overmars (2009). "Combining top-down and bottom-up dynamics in land use modeling: exploring the future of abandoned farmlands in Europe with the Dyna-CLUE model." Landscape Ecology 24(9): 1167-1181. 
873 Verburg, P. H., J. van de Steeg, A. Veldkamp and L. Willemen (2009). "From land

874

875

876

877

878

879

880

881

882 cover change to land function dynamics: A major challenge to improve land characterization." Journal of Environmental Management 90(3): 1327-1335.

Volk, M. and F. Ewert (2011). "Scaling methods in integrated assessment of agricultural systems - State-of-the-art and future directions." Agriculture, Ecosystems \& Environment 142(1-2): 1-5.

Wu, J. (2010). "Landscape of culture and culture of landscape: Does landscape ecology need culture?" Landscape Ecology 25(8): 1147-1150. 
883

884 Figure 1. Schematic representation of the whole methodological framework of MSIF

885

886

887

888

889

890

891

892

893

894

895

896

897

898

899

Figure 2. The participatory workshop in action

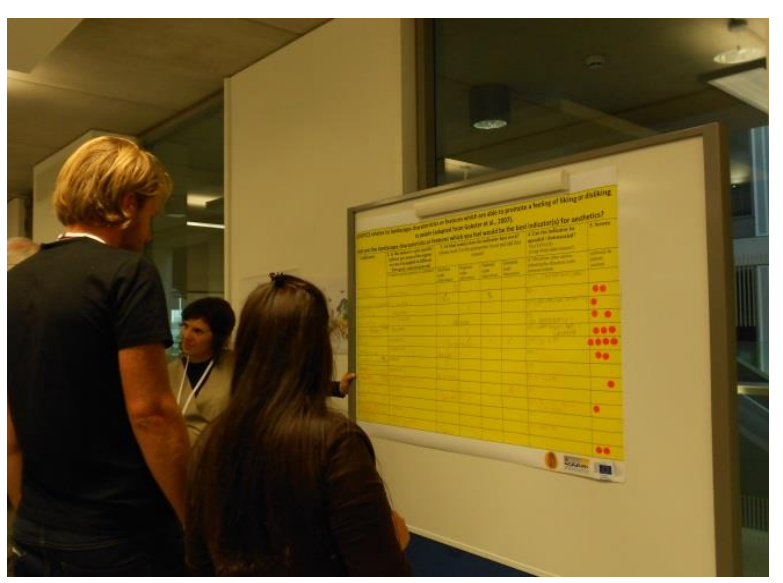

Participatory Workshop

Attributes,

elements, $\longrightarrow$ Scale at which features $\longrightarrow$ can be related to $\quad$ measured? the different C/VC/CES

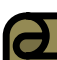

Indicators

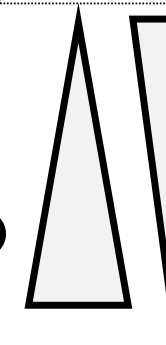

\section{Tool for policy} making and monitoring of Cultural ES

Ratio land use/land cover

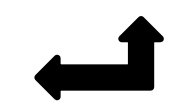

1

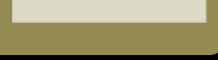


902 Tables

903 Table 1. Criteria and related definitions

\begin{tabular}{ll}
\multicolumn{1}{c}{ Criteria } & \multicolumn{1}{c}{ Definition } \\
\hline STEWARDSHIP & $\begin{array}{l}\text { Refers to the sense of order and care present in the landscape } \\
\text { reflecting active and careful management (Ode Sang and Tveit, } \\
\text { 2013). }\end{array}$ \\
\hline DIVERSITY & $\begin{array}{l}\text { Is defined as the richness and diversity of landscape elements and } \\
\text { features noted for their proximity and location, as well as the } \\
\text { grain size of the landscape (Tveit et al., 2006). }\end{array}$ \\
\hline AESTHETICS & $\begin{array}{l}\text { Relates to landscape characteristics or features which are able to } \\
\text { promote a feeling of liking or disliking (adapted from Gobster et } \\
\text { al., 2007). }\end{array}$ \\
\hline
\end{tabular}

904

905 Table 2. List of measures/indicators derived from the workshop and its preliminary

906 assessment 


\begin{tabular}{|c|c|c|c|c|c|c|}
\hline : & Indicators & : & 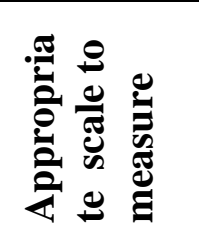 & 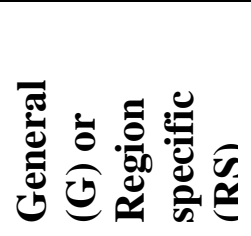 & 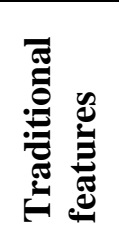 & 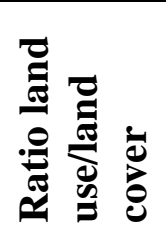 \\
\hline \multirow{8}{*}{ 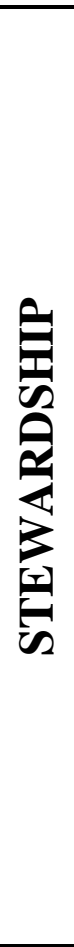 } & $\begin{array}{l}\text { The "quality" of man- made structures } \\
\text { (hedges in good condition status and made } \\
\text { with local resources e.g. stone walls) }\end{array}$ & 5 & $\mathrm{~S}, \mathrm{~L} ; \mathrm{N}$ & $\mathrm{G}^{*}$ & $\mathrm{X}$ & \\
\hline & $\begin{array}{l}\text { Regularity of the landscapes (as man } \\
\text { introduces regular shapes) number of man- } \\
\text { made structures with a function: hedges, }\end{array}$ & 5 & $\mathrm{~S}, \mathrm{~L} ; \mathrm{N}$ & $\mathrm{G}^{*}$ & $\mathrm{X}$ & \\
\hline & $\begin{array}{l}\text { Adequate stocking rate of livestock- } \\
\text { according to environmental conditions }\end{array}$ & 2 & $\mathrm{~S}, \mathrm{~L}, \mathrm{R}$ & $\mathrm{G}^{*}$ & $\mathrm{X}$ & $\mathrm{X}$ \\
\hline & $\begin{array}{l}\text { "Knowledgeable and wise" land } \\
\text { management (multifunctionality, different } \\
\text { uses of the same plot) }\end{array}$ & & S,L,R & $\mathrm{G}^{*}$ & & $\mathrm{X}$ \\
\hline & Maintaining traditional irrigation systems & & $\mathrm{S}, \mathrm{L}, \mathrm{R}$ & $\mathrm{RS}$ & $\mathrm{X}$ & \\
\hline & $\begin{array}{l}\text { Amount of shrubs in agriculture/ forest } \\
\text { land - stewardship might also mean low } \\
\text { vertical diversity- }\end{array}$ & & $\mathrm{S}, \mathrm{L} ; \mathrm{N}$ & $\mathrm{G}^{*}$ & & $\mathrm{X}$ \\
\hline & $\begin{array}{l}\text { Land abandonment and discontinuation of } \\
\text { farming (is seen as negative) }\end{array}$ & & $\mathrm{S}, \mathrm{L} ; \mathrm{N}$ & $\mathrm{G}^{*}$ & $\mathrm{X}$ & \\
\hline & No waste & & $\mathrm{S}, \mathrm{L}, \mathrm{R}$ & $\mathrm{G}$ & & \\
\hline \multirow{9}{*}{ 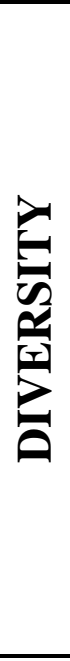 } & Hedges between agriculture and other uses & & $\mathrm{S}, \mathrm{L}, \mathrm{R}$ & $\mathrm{G}^{*}$ & $X$ & \\
\hline & $\begin{array}{l}\text { Richness-number of elements, land cover } \\
\text { types in a view shed }\end{array}$ & 7 & $\mathrm{~S}, \mathrm{~L}, \mathrm{R}, \mathrm{N}, \mathrm{E}$ & $\mathrm{G} *$ & & $\mathrm{X}$ \\
\hline & Diversity of high-shanon,gini,simpson & 6 & $\mathrm{~S}, \mathrm{~L}, \mathrm{R}, \mathrm{N}, \mathrm{E}$ & $\mathrm{G}^{*}$ & & $\mathrm{X}$ \\
\hline & $\begin{array}{c}\text { Types of use per land covers (e.g. grass } \\
\text { and trees) }\end{array}$ & 3 & $\mathrm{~S}, \mathrm{~L}, \mathrm{R}$ & $\mathrm{G}^{*}$ & & $\mathrm{X}$ \\
\hline & $\begin{array}{c}\text { Number of endemic plant/animal species } \\
\text { per ha }\end{array}$ & 3 & $\mathrm{~S}, \mathrm{~L}, \mathrm{R}$ & $\mathrm{G}^{*}$ & & $\mathrm{X}$ \\
\hline & $\begin{array}{l}\text { Presence of trees/woodlands in field (no } \\
\text { agreement) }\end{array}$ & 2 & $\mathrm{~S}, \mathrm{~L}, \mathrm{R}$ & $\mathrm{G}^{*}$ & & $X$ \\
\hline & Diversity of use in time & & $\mathrm{S}, \mathrm{L}, \mathrm{R}$ & $\mathrm{G}^{*}$ & $\mathrm{X}$ & $\mathrm{X}$ \\
\hline & Number of crops in crop rotation & & $\mathrm{S}, \mathrm{L}, \mathrm{R}$ & $\mathrm{G}^{*}$ & $\mathrm{X}$ & $\mathrm{X}$ \\
\hline & Vertical diversity & & $\mathrm{S}, \mathrm{L}, \mathrm{R}$ & $\mathrm{G}^{*}$ & & $\mathrm{X}$ \\
\hline \multirow{7}{*}{ 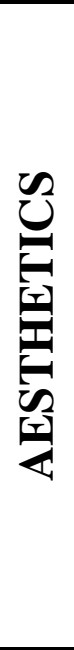 } & $\begin{array}{l}\text { Water bodies (no agreement) society in } \\
\text { general likes water bodies-but not all of } \\
\text { them... }\end{array}$ & 4 & $\mathrm{~S}, \mathrm{~L}, \mathrm{R}, \mathrm{N}, \mathrm{E}$ & $\mathrm{G}^{*}$ & & \\
\hline & Sublime features e.g. mountains & 4 & $\mathrm{~S}, \mathrm{~L}, \mathrm{R}, \mathrm{N}, \mathrm{E}$ & $\mathrm{G}^{*}$ & & \\
\hline & $\begin{array}{l}\text { No litter } \\
\end{array}$ & 3 & $\mathrm{~S}, \mathrm{~L}, \mathrm{R}, \mathrm{N}, \mathrm{E}$ & $\mathrm{G}^{*}$ & & \\
\hline & $\begin{array}{l}\text { Variety of colours/smell e.g. different land } \\
\text { uses on a single land cover (no agreement } \\
\text { as too much variety might be confusing) }\end{array}$ & 3 & $\mathrm{~S}, \mathrm{~L}$ & $\mathrm{G}^{*}$ & $\mathrm{X}$ & $\mathrm{X}$ \\
\hline & $\begin{array}{c}\text { Number of listed trees classified as } \\
\text { monuments in agrarian areas }\end{array}$ & 2 & $\mathrm{~S}, \mathrm{~L}, \mathrm{~N}$ & $\mathrm{G}^{*}$ & & $\mathrm{X}$ \\
\hline & $\begin{array}{c}\text { Density of classified trees in agricultural } \\
\text { landscapes }\end{array}$ & 1 & $\mathrm{~S}, \mathrm{~L}, \mathrm{~N}$ & $\mathrm{G}^{*}$ & & $X$ \\
\hline & "Old landscapes still functional", time & 2 & $\mathrm{~S}, \mathrm{~L}$ & $\mathrm{G}^{*}$ & $X$ & $X$ \\
\hline
\end{tabular}




\begin{tabular}{|c|c|c|c|c|}
\hline depth, time origin is long & & & & \\
\hline Listed built elements & 1 & $\mathrm{~S}, \mathrm{~L}, \mathrm{~N}$ & $\mathrm{G}^{*}$ & $\bar{X}$ \\
\hline Sound/tranquillity & & $\mathrm{S}, \mathrm{L}, \mathrm{N}$ & $\mathrm{G}^{*}$ & \\
\hline $\begin{array}{l}\text { Features associated with stewardship (no } \\
\text { agreement) we like to see cared for rural } \\
\text { areas, neat, ordered and clean }\end{array}$ & & S,L,N & $\mathrm{RS}$ & $\bar{X}$ \\
\hline $\begin{array}{l}\text { Amount of waste and decay of man-made } \\
\text { structures (is seen as negative) }\end{array}$ & & $\mathrm{S}, \mathrm{L}, \mathrm{N}$ & $\mathrm{G}^{*}$ & $\bar{X}$ \\
\hline Light pollution (negative) & & $\mathrm{S}, \mathrm{L}, \mathrm{N}$ & $\mathrm{G}$ & \\
\hline
\end{tabular}

907

908 


\begin{tabular}{|c|c|c|}
\hline $\begin{array}{r}\text { Advantages } \\
\end{array}$ & Disadvantages & Ways to improve the approach \\
\hline $\begin{array}{l}\text { The division of participants into small groups is } \\
\text { useful: } \\
\text { - gives time for all participants to contribute and } \\
\text { encourages participation from less confident } \\
\text { individuals, } \\
\text {-the cross-talk taking place in the small groups } \\
\text { provided an opportunity for participants to learn } \\
\text { from each other. } \\
\text { - the fact that there is very little structured } \\
\text { process that needed to be followed meant that } \\
\text { individuals were allowed to contribute as much } \\
\text { or as little as they wanted; the process did not } \\
\text { dominate the spirit of the group. }\end{array}$ & $\begin{array}{l}\text { Because there was little opportunity to discuss the } \\
\text { merits of ideas within the whole group, there is a } \\
\text { danger that the merit of good ideas might be missed } \\
\text { by the wider group through lack of understanding. }\end{array}$ & $\begin{array}{l}\text { Provide more time for the plenary discussion-This } \\
\text { can be done by for example reducing the time in the } \\
\text { stations. It might have been better to allow more time } \\
\text { for the first round of small group discussions and less } \\
\text { time for subsequent rounds instead of a fixed } 15 \\
\text { minutes in each station. When a group comes to a } \\
\text { station previously occupied by other groups, they are } \\
\text { building on the information already provided by the } \\
\text { earlier group(s), i.e. some of the thinking has already } \\
\text { been done. }\end{array}$ \\
\hline $\begin{array}{l}\text { The process of dissolving groups between } \\
\text { stations was useful in that it altered the dynamics } \\
\text { of the groups, particularly breaking up negative } \\
\text { interactions between individuals, such as } \\
\text { dominance of passive by assertive individuals. }\end{array}$ & $\begin{array}{l}\text { As the group was changing every } 15 \text { minutes there } \\
\text { was not a lot of opportunity for the testing of the } \\
\text { merits of ideas being suggested by participants } \\
\text { cross-questioning. }\end{array}$ & $\begin{array}{l}\text { Organize a second round of voting after the plenary } \\
\text { session. If there had been wider discussion of the ideas } \\
\text { raised a second round of voting would have been } \\
\text { possible, so that participants could revise their } \\
\text { opinions in light of new information received in the } \\
\text { plenary discussion. This will also encourage } \\
\text { participants cross questioning }\end{array}$ \\
\hline $\begin{array}{l}\text { The very explicitly goal oriented tasks, coupled } \\
\text { with clear instructions of a straightforward } \\
\text { methodology, meant that there was little wastage } \\
\text { of time (in clarifying purpose of methods) and }\end{array}$ & The facilitation process was not homogeneous. & $\begin{array}{l}\text { To give more "strict rules" to the stations } \\
\text { facilitators in order to have similar processes } \\
\text { occurring in the different stations. (Rules and ways to } \\
\text { proceed were given to facilitators beforehand, }\end{array}$ \\
\hline
\end{tabular}




\begin{tabular}{l|l|l}
\hline $\begin{array}{l}\text { participants could be productive immediately. } \\
\text { The use of strictly time-constrained tasks kept } \\
\text { participants focussed and maintained energy. }\end{array}$ & & however, different facilitations styles were obvious.) \\
\hline $\begin{array}{l}\text { It was beneficial that there was no requirement to } \\
\text { achieve group agreement within the small groups } \\
\text { at the point of identifying issues. This } \\
\text { encouraged the generation of more speculative } \\
\text { and controversial ideas,; i.e. there was no } \\
\text { inhibition derived from anticipation of counter } \\
\text { argument. }\end{array}$ & $\begin{array}{l}\text { Some participants got confused and did not } \\
\text { understand well the other participant's ideas. } \\
\text { Furthermore some participants felt sad that one idea } \\
\text { because other participants views. }\end{array}$ & \\
\hline $\begin{array}{l}\text { There was no top-down input thus the risk of } \\
\text { biasing the outputs of participants is small. } \\
\text { Participants came from a range of disciplines and } \\
\text { geographical regions, providing greater } \\
\text { heterogeneity of ideas. Anonymous voting for } \\
\text { favoured ideas eliminated any residual } \\
\text { 'dominant character' effect. }\end{array}$ & $\begin{array}{l}\text { Discussions were sometime confusing. Concepts } \\
\text { were not common to all participants. }\end{array}$ & \\
\hline
\end{tabular}


912 Annexe 1. Assessment of the workshop indicators using the criteria listed by Tveit et al 913 (2006) 